\title{
Secular trends in suicidal ideation and associated factors among adolescents
}

\author{
Fernanda C. Soares, ${ }^{1}$ iD Carla M. Hardman, ${ }^{2}$ João F.B. Rangel Junior, ${ }^{1}$ Jorge Bezerra, ${ }^{1}$ \\ Kátia Petribú, ${ }^{3}$ Jorge Mota, ${ }^{4}$ Mauro V.G. de Barros, ${ }^{1}$ Rodrigo A. Lima ${ }^{1,5}$
}

${ }^{1}$ Escola de Educação Física, Programa de Pós-Graduação em Educação Física, Grupo de Pesquisa em Estilos de Vida e Saúde (GPES), Universidade de Pernambuco (UPE), Recife, PE, Brazil. ${ }^{2}$ Programa de Pós-Graduação em Educação Física, Universidade Federal de Pernambuco, (UFPE), Recife, PE, Brazil. ${ }^{3}$ Faculdade de Ciências Médicas, UPE, Recife, PE, Brazil. ${ }^{4}$ Centro de Investigação em Atividade Física, Saúde e Lazer (CIAFEL), Faculdade de Desporto, Universidade do Porto, Porto, Portugal. ${ }^{5}$ Institut für Sportwissenschaft, Karl-FranzensUniversität Graz, Graz, Austria.

\begin{abstract}
Objectives: Suicide is one of the leading causes of death in adolescence, and the second most common cause of death among young people. The objective of this study was to identify trends in suicidal ideation by sex and ascertain factors associated with this outcome.

Methods: Secular trend study with statewide coverage conducted at 5-year intervals, with 4,207 adolescents (2006), 6,264 adolescents (2011) and 6,026 adolescents (2016). Logistic regression was used to evaluate the secular trend of suicidal ideation. Multilevel logistic regressions evaluated the factors associated with suicidal ideation in the survey conducted in 2016.

Results: There was a positive trend in suicidal ideation prevalence in 2016 compared to the prevalence in 2006 and 2011, in both boys and girls. Low social support, poor sleep quality, and low parental supervision were associated with suicidal ideation in boys and girls. Exposure to violence and bullying was associated with suicidal ideation only in girls. TV time and computer and videogame time were not associated with suicidal ideation in boys or girls.

Conclusion: There is an alarming trend of increased suicidal ideation in adolescents. Several dimensions were associated with suicidal ideation in adolescents, especially social support, sleep quality, and parental supervision.
\end{abstract}

Keywords: Suicidal ideation; secular trend; adolescents

\section{Introduction}

Suicide is a serious public health problem with great social, economic, and personal impact, ${ }^{1}$ and is considered an indirect indicator of the mental health status of the population. ${ }^{2}$ Suicide is one of the leading causes of death in adolescence, being the second most common cause of death among individuals aged 15-29 years worldwide, ${ }^{3}$ and the fourth leading cause of death in this age group in Brazil. ${ }^{4}$ It is a multidimensional behavior that results from multiple interactions among genetic, biological, psychiatric, psychological, social, and cultural factors. ${ }^{5}$

Suicide deserves special attention in adolescence, as it is a period of biopsychosocial development that can be marked by conflicts and distress ${ }^{6}$ and is strongly associated with death from external causes. ${ }^{7}$ Suicidal behavior is a spectrum that includes suicidal ideation (thoughts, ideas, planning, and desire to commit suicide), attempted suicide, and completed suicide. ${ }^{8}$ Turecki \& Brent suggest the presence of a possible gradient of severity and heterogeneity between these different categories. ${ }^{9}$

Correspondence: Fernanda C. Soares, Universidade de Pernambuco (UPE), Rua Arnóbio Marques, 310, Santo Amaro, CEP 50100130, Recife, PE, Brazil.

E-mail: fercsoares@gmail.com

Submitted Nov 11 2019, accepted Jan 26 2020, Epub Jun 012020.
Suicidal ideation during adolescence is quite common. ${ }^{10}$ Studies indicate that its prevalence is relatively high in adolescents, ranging from around $6.0 \%$ in Philadelphia ${ }^{11}$ to $31.5 \%$ in Hungary. ${ }^{12}$ In Brazil, the prevalence of suicidal ideation in this population subgroup has varied widely, from 8.0 to $36.0 \%{ }^{13}$ Moreover, the suicide rate among Brazilian adolescents increased by $24 \%$ in six large Brazilian cities and by $13 \%$ in the country as a whole between 2006 and $2015 .^{4}$

Trends in suicidal ideation seem to differ between boys and girls. ${ }^{10,14,15}$ However, whether this is true in Brazil is still unknown. Moreover, it is also uncertain whether the determinants of suicidal ideation in Brazilian youth are dependent on their sex.

Review studies have shown that depression, hopelessness, psychiatric disorders, impulsivity, and posttraumatic stress disorder are the main risk factors associated with suicidal ideation in adolescents. ${ }^{16,17}$ Belfort \& Miller revealed that social media is linked to suicidal ideation, but the relationship is complex and not necessarily causal. ${ }^{18}$ Drapeau \& Nadorff indicated that sleep disorders are

How to cite this article: Soares FC, Hardman CM, Rangel Junior JFB, Bezerra J, Petribú K, Mota J, et al. Secular trends in suicidal ideation and associated factors among adolescents. Braz J Psychiatry. 2020;42:475-480. http://dx.doi.org/10.1590/1516-44462019-0783 
associated with suicidal ideation. ${ }^{19}$ This corroborates that the factors associated with suicidal ideation during adolescence are multifaceted, and include demographic characteristics such as female gender, low economic status, mental disorders (depression), alcohol and drug use, physical violence, parenting problems, sadness, and solitude. ${ }^{20}$

Although there is some published evidence on the determinants of suicidal ideation, most studies have evaluated risk factors individually, ${ }^{21}$ not accounting for their interrelationship, which can have an additive impact on the strength of the association between factor and ideation in adolescents. Therefore, in addition to describing secular trends in suicidal ideation, we evaluated the factors associated with this behavior in adolescents. We hypothesized that the secular trend of suicidal ideation would have increased from 2006 to 2016, and that the factors associated with suicidal ideation would differ depending on sex.

\section{Methods}

This is a school-based study and part of a larger project, Prática de Atividades Físicas e Comportamentos de Risco à Saúde em Estudantes do Ensino Médio no Estado de Pernambuco: Estudo de Tendência Temporal (2006-2011-2016) - Projeto ATITUDE (Practice of Physical Activities and Health Risk Behaviors in Secondary Students in the State of Pernambuco: a Time Trend Study). The target population consists of students attending the first, second, and third years of secondary education at public schools in the state of Pernambuco. Cross-sectional surveys were carried out in 2006, 2011, and 2016.

As detailed information about ATITUDE is available elsewhere, ${ }^{22}$ only those variables of interest to the present study will be described in this manuscript. The sample calculation from the three surveys considered a $95 \%$ confidence interval, a maximum tolerable error of $2 \%$, and an estimated prevalence of variables of $50 \%$. In addition, a correction (design effect - deff) was applied considering a two-stage cluster sampling strategies (schools and classes). In 2006, the adopted deff was 4, while the deff in 2011 and 2016 was 2. The minimum sample was inflated by $20 \%$ in all surveys due to losses and refusals. In 2006, 4,207 adolescents (14-19 years) were monitored, while 6,264 and 6,026 adolescents were included in the 2011 and 2016 surveys, respectively. Data were collected through the Global School-based Student Health Survey (GSHS) as proposed by the WHO, with the objective of evaluating the exposure to health risk behaviors in adolescents. The dependent variable of the study was suicidal ideation, obtained through the dichotomous question: "During the last 12 months, have you seriously considered attempting suicide?" As detailed below, factor analysis was performed to group the questions into dimensions (Table 1).

\section{Statistical analyses}

All statistical analyses were performed in STATA 13 for Windows. Descriptive differences in each variable between boys and girls were assessed using the chi-square test. A logistic regression using the year of the survey as an independent variable was run to assess secular trends in suicidal ideation for 2006, 2011, and 2016.

\section{Factor analysis}

Principal component analysis was performed to group the variables into dimensions. First, an exploratory factor analysis was performed with all possible variables described in Table 1. The composition of each dimension was determined by the factor loadings of each variable. Variables with a Kaiser-Meyer-Olkin value equal to or greater than 0.5 were included in their respective dimension. Table 1 also presents the dimensions that resulted from the factor analysis. Of the 28 variables included in the exploratory factor analysis, 20 variables composed eight dimensions. In all dimensions, a higher score represents a more negative behavior. For instance, in the dimension "TV time," a higher score represents more hours per day spent watching TV on weekdays and during the weekend.

\section{Factors associated with suicidal ideation}

Multilevel logistic regressions were used to analyze the association between the dimensions and suicidal ideation in 2016. As a first step, we tested the association between each dimension and suicidal ideation in 2016. Dimensions with $p \leqslant 0.05$ in the crude model were further adjusted for age and maternal educational attainment (adjusted model). The variance related to the clusters (region and school) in all multilevel regression models was considered in the analyses, and the intraclass correlation coefficient (ICC) was calculated to interpret the variation at each cluster level (individuals nested within schools and schools nested within regions). Most of the variation in all regression models was at the individual level, so the combined variance of the regions and schools was always below $5 \%$. All multilevel logistic regressions presented good model fit according to the Hosmer-Lemeshow test $(p>0.05) .{ }^{23}$ The results are presented as odds ratios and $95 \%$ confidence intervals. We accepted a $5 \%$ error rate in all analyses.

\section{Ethics statement}

The research protocol was approved by the research ethics committee of Universidade de Pernambuco (CAAE 56341416.9.0000.5192/CEP-UPE). All parents/guardians and participants provided written informed consent and assent, respectively.

\section{Results}

The mean age of the adolescents was $16.8 \pm 1.4$ years, $16.6 \pm 1.3$ years, and $16.5 \pm 1.2$ years in 2006,2011 , and 2016 , respectively. In $2006,62.8 \%$ of the mothers studied for less than eight years, followed by $55.0 \%$ in 2011 and $46.1 \%$ in 2016. In all the surveys, females were more prevalent: $59.8 \%$ (2006), $59.7 \%(2011)$ and $55.3 \%$ (2016). 
Table 1 Description of the variables and their respective categorizations

\begin{tabular}{|c|c|c|}
\hline Questions & Answer categories & Composed dimensions \\
\hline $\begin{array}{l}\text { TV time (week) ( }>5 \text { hours/day) } \\
\text { TV time (weekend) }(>5 \text { hours/day) }\end{array}$ & $\begin{array}{l}\text { Yes; No } \\
\text { Yes; No }\end{array}$ & TV time \\
\hline $\begin{array}{l}\text { Game time* (week) ( }>5 \text { hours/day) } \\
\text { Game time* (weekend) }(>5 \text { hours/day) }\end{array}$ & $\begin{array}{l}\text { Yes; No } \\
\text { Yes; No }\end{array}$ & Computer and videogame time \\
\hline $\begin{array}{l}\text { Feeling sad } \\
\text { Feeling lonely } \\
\text { Parents understand my problems }\end{array}$ & $\begin{array}{l}\text { Yes; No } \\
\text { Yes; No } \\
\text { Yes; No }\end{array}$ & Social support \\
\hline $\begin{array}{l}\text { Missing classes without consent } \\
\text { Religious practice }\end{array}$ & $\begin{array}{l}\leqslant 2 \text { days; }>2 \text { days } \\
\text { Yes; No }\end{array}$ & Parental supervision \\
\hline $\begin{array}{l}\text { Age at onset of alcohol intake } \\
\text { Age at onset of drug intake } \\
\text { Age at first sexual intercourse }\end{array}$ & $\begin{array}{l}\text { Never } ; \leqslant 13 \text { years } ; \geqslant 14 \text { years } \\
\text { Never; } \leqslant 13 \text { years; } \geqslant 14 \text { years } \\
\text { Never; } \leqslant 13 \text { years } ; \geqslant 14 \text { years }\end{array}$ & Health risk behavior \\
\hline $\begin{array}{l}\text { Could not sleep because of worry/stress } \\
\text { Sleep quality } \\
\text { Hours of sleep }\end{array}$ & $\begin{array}{l}\text { Yes; No } \\
\text { Excellent/good; Fair/poor } \\
<6 \text { hours; } \geqslant 6 \text { hours }\end{array}$ & Sleep quality \\
\hline $\begin{array}{l}\text { Experienced violence in the last month } \\
\text { Number of fights involved in the last month } \\
\text { Experienced bullying }\end{array}$ & $\begin{array}{l}\text { Yes; No } \\
\text { Never; } 1 \text { to } 3 ; \geqslant 4 \\
\text { Yes; No }\end{array}$ & Violence and bullying \\
\hline $\begin{array}{l}\text { Was assaulted, attacked, or abused } \\
\text { Something caused an injury }\end{array}$ & $\begin{array}{l}\text { Yes; No } \\
\text { Yes; No }\end{array}$ & Aggression \\
\hline $\begin{array}{l}\text { Do you regularly perform some type of physical activity } \\
\text { in your leisure time? } \\
\text { Are your colleagues friendly and helpful towards you? } \\
\text { Do you have friends? } \\
\text { Did you have binge drinking behavior in the last month? } \\
\text { How many times did you use drugs in the last month? } \\
\text { How many sexual partners have you had ever? } \\
\text { In general, how would you describe your health? } \\
\text { Do you practice your religion? }\end{array}$ & $\begin{array}{l}\text { Yes; No } \\
\text { Yes; No } \\
\text { Yes; No } \\
\text { Yes / No } \\
1 \text { to } 2 \text { times; } \geqslant 3 \text { times } \\
1 \text { to } 2 \text { partners; } \geqslant 3 \text { partners } \\
\text { Excellent/good; Fair/poor } \\
\text { Yes; No }\end{array}$ & $\begin{array}{l}\text { Variables not included in any } \\
\text { dimension }(\mathrm{KMO}<0.5)\end{array}$ \\
\hline
\end{tabular}

* Game time refers to both computer and video games.

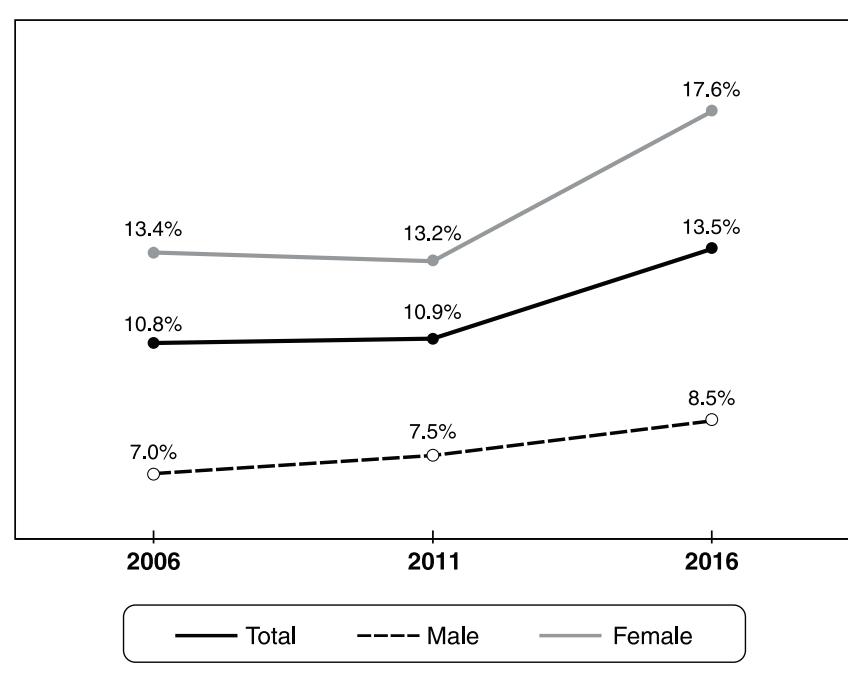

Figure 1 Time trend of suicidal ideation from 2006-2011 and 2011-2016, stratified by sex.

There was no trend in the prevalence of suicidal ideation from 2006 to 2011. On the other hand, a significant upward trend was identified in the 2016 survey in comparison to the previous surveys $(p<0.001)$. This increasing trend in suicidal ideation was also observed for male and female adolescents separately. In all surveys, the prevalence of suicidal ideation in females was twice the rate observed in males (Figure 1).

Table 2 presents descriptive differences in each variable in relation to sex. Missing classes without consent, hours of sleep, having experienced bullying, and both questions related to aggression (being assaulted and suffered injury) were the only variables not to differ between sexes (Table 2).

Table 3 presents the dimensions associated with suicidal ideation in the 2016 survey for boys and girls. Regardless of sex, low social support, poor sleep quality, and lower parental supervision were the dimensions most strongly associated with suicidal ideation in adolescents. In addition to those dimensions, being exposed to violence and bullying and to aggression were associated with suicidal ideation in girls (Table 3 ).

\section{Discussion}

The present investigation analyzed the secular trend of suicidal ideation and its associated factors in adolescents from the state of Pernambuco, Brazil. Confirming our hypothesis, the prevalence of suicidal ideation increased 
Table 2 Prevalence of each risk behavior in its respective dimension, stratified by sex

\begin{tabular}{|c|c|c|c|}
\hline \multirow[b]{2}{*}{ Dimensions/questions } & \multirow{2}{*}{$\frac{\text { Male }}{\mathrm{n}(\%)}$} & \multirow{2}{*}{$\frac{\text { Female }}{\mathrm{n}(\%)}$} & \multirow[b]{2}{*}{$\mathrm{p}$-value } \\
\hline & & & \\
\hline \multicolumn{4}{|l|}{ TV time } \\
\hline TV time ( $>5$ hours/day during the weekdays)* & $223(8.5)$ & $353(10.9)$ & $<0.01$ \\
\hline TV time ( $>5$ hours/day during the weekends)* & $404(15.5)$ & $233(7.3)$ & $<0.01$ \\
\hline \multicolumn{4}{|l|}{ Computer and videogame time } \\
\hline Game time ( $>5$ hours/day during the weekdays)* & $391(15.0)$ & $176(5.5)$ & $<0.01$ \\
\hline Game time ( $>5$ hours/day during the weekends)* & $653(25.3)$ & $283(8.9)$ & $<0.01$ \\
\hline \multicolumn{4}{|l|}{ Social support } \\
\hline Feeling sad (yes) ${ }^{\dagger}$ & $576(21.8)$ & $1,190(36.3)$ & $<0.01$ \\
\hline Feeling lonely (yes) $)^{\dagger}$ & $1,321(49.6)$ & $2,240(67.9)$ & $<0.01$ \\
\hline Parents understand my problems (yes) ${ }^{\dagger}$ & $1,218(45.9)$ & $1,608(48.9)$ & 0.02 \\
\hline \multicolumn{4}{|l|}{ Parental supervision } \\
\hline Missing classes without consent (yes) ${ }^{\dagger}$ & $447(16.8)$ & $538(16.3)$ & 0.66 \\
\hline Religious practice $(\mathrm{no})^{\ddagger}$ & $1,203(45.4)$ & $1,132(34.4)$ & $<0.01$ \\
\hline \multicolumn{4}{|l|}{ Health risk behaviors } \\
\hline Age at onset of alcohol use ${ }^{\S}$ & & & $<0.01$ \\
\hline$\leqslant 13$ years & $769(28.8)$ & $793(24.1)$ & \\
\hline$\geqslant 14$ years & $962(36.1)$ & $1,379(41.8)$ & \\
\hline Age at onset of drug use ${ }^{\S}$ & & & $<0.01$ \\
\hline$\leqslant 13$ years & $107(4.1)$ & $52(1.6)$ & \\
\hline$\geqslant 14$ years & $285(10.8)$ & $222(6.8)$ & \\
\hline Age at first sexual intercourse ${ }^{\S}$ & & & $<0.01$ \\
\hline$\leqslant 13$ years & $355(14.3)$ & $157(4.8)$ & \\
\hline$\geqslant 14$ years & $1,084(43.6)$ & $1,046(31.8)$ & \\
\hline \multicolumn{4}{|l|}{ Sleep quality } \\
\hline Could not sleep because of worry/stress (yes) ${ }^{\dagger}$ & $1,102(41.2)$ & $2,029(61.4)$ & $<0.01$ \\
\hline Sleep quality (poor) & $739(27.7)$ & $1,189(36.0)$ & $<0.01$ \\
\hline Hours of sleep $(<6 \text { hours })^{\uparrow}$ & $1,031(38.7)$ & $1,294(39.4)$ & 0.58 \\
\hline \multicolumn{4}{|l|}{ Violence and bullying } \\
\hline Experienced violence in the last month (yes) ${ }^{\dagger}$ & $397(14.9)$ & $385(11.7)$ & $<0.01$ \\
\hline Number of fights involved in the last month $(\geqslant 4)$ & $172(6.5)$ & $68(2.1)$ & $<0.01$ \\
\hline Experienced bullying (yes) ${ }^{\dagger}$ & $495(18.6)$ & $620(18.8)$ & 0.84 \\
\hline \multicolumn{4}{|l|}{ Aggression } \\
\hline Was assaulted, attacked or abused (yes) ${ }^{\dagger}$ & $9(0.4)$ & $21(0.6)$ & 0.11 \\
\hline Something caused an injury (yes) ${ }^{\dagger}$ & $44(1.7)$ & $72(2.2)$ & 0.14 \\
\hline
\end{tabular}

$* \leqslant 5$ hours/day; ${ }^{\dagger}$ no; ${ }^{\S}$ never; ${ }^{\ddagger}$ yes; ${ }^{\prime \prime}$ good; ${ }^{\uparrow} \geqslant 6$ hours.

Chi-square test.

in both boys (8.4\%) and girls (17.7\%) in 2016 compared to 2006 (boys: 7.1\%; girls: 14.0\%) and 2011 (boys: 7.4\%; girls: $13.7 \%$ ). Social support, sleep quality, and parental supervision were the factors most strongly associated with suicidal ideation, regardless of sex.

Our investigation highlights the impact of social support on the likelihood of suicidal ideation in adolescents. Social support was the single factor most strongly associated with suicidal ideation in both males and females. Troubled relationships have a strong influence on adolescent mental health. Conflicts with boyfriends, friends, and family increase the odds of suicidal ideation. ${ }^{24}$ Loneliness is often a primary reason for suicidal behaviour ${ }^{25}$; thus, friendship problems are intrinsically associated with a trend toward suicide among adolescents. ${ }^{26}$ Breakups are often considered one of the leading sources of stress among adolescents, and such stress may indirectly influence suicidal ideations. ${ }^{27}$ Schools seem the ideal location for targeting adolescents' social networks. Governments should implement strategies to broaden and strengthen the net of social support among adolescents at school, since most adolescents, even in developing countries, spend most of the time with their peers in this environment.

Sleep quality was the second strongest dimension associated with suicidal ideation, again independently of sex. Several studies have identified relationships between sleep disorders, depression, suicidal ideation, and suicide. ${ }^{28}$ Adolescents need many hours of sleep, due to changes in melatonin and sleep hormones. ${ }^{29}$ Nine hours of sleep a night are recommended, although most adolescents do not comply with this advice ${ }^{30}$; this leads to serotonergic dysregulation and reduced secretion of serotonin, which controls mood, anxiety, and impulsivity, ultimately causing emotional instability. ${ }^{30}$

Parental supervision was also associated with suicidal ideation for both boys and girls. This dimension was composed of two questions: missing class without consent of 


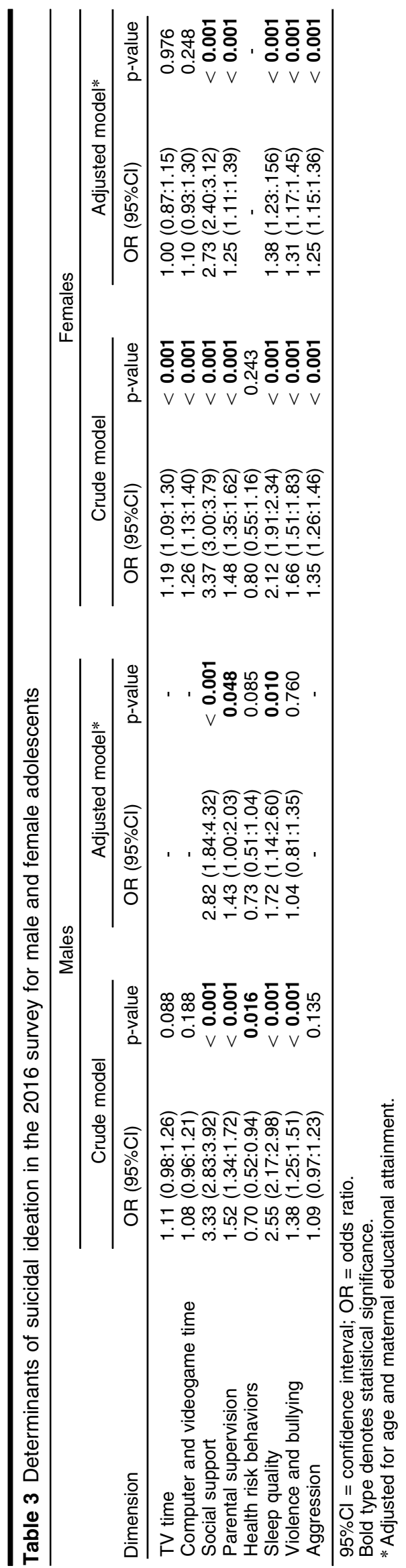

a parent/guardian and religious practices. It is possible that religious practice helped adolescents cope better with life stresses and attenuated the risk of developing depression and substance misuse. Moreover, religious practices might be an additional source of social support, as well as of hope and meaning in life. ${ }^{31}$ In addition, most religions condemn suicide and provide a series of coping strategies (e.g., prayer, rituals, religious services, social networks) that may have helped believers manage their difficulties, thus reducing the risk of suicide ideation. ${ }^{32}$

Exposure to violence, bullying, and aggression increased the odds of suicidal ideation in adolescent girls. Violence experienced by adolescents at the hand of schoolmates or other close persons also increases the odds of suicidal ideation. ${ }^{33}$ High levels of aggression during life are associated with high risk of suicide. ${ }^{34}$ Most adolescents who are involved in fights or bullying endure consistent psychological pressure, and may view suicide or homicide as the only way out to relieve their suffering. ${ }^{35}$ Family violence and instability, physical and sexual abuse, and the two extremes of parental authoritarianism and loss of parental authority have all been considered risk factors for suicidal behavior in adolescents. ${ }^{36}$

The higher prevalence of suicide ideation in females has been demonstrated in several studies. ${ }^{37,38}$ Women are more critical of themselves, face more internal conflicts, and are more likely to experience depression and anxiety. ${ }^{37}$ Furthermore, women usually cope with professional, domestic, economic and academic problems concomitantly, which can ultimately increase suicidal ideation. ${ }^{37}$

The results of the present study should be interpreted with caution. This is a panel study and, therefore, does not allow any inference about causality. Factors were selected from specialized literature, but interpretations of cause and effect must be made carefully. It is possible that the prevalence of suicidal ideation is even greater than presented herein. Although the nature of the study was explained and assurances of anonymity were provided, adolescents may have felt insecure or ashamed to admit socially unacceptable behaviors. In addition, we did not take into account the number of times adolescents may have experienced suicidal ideation, since the question: "During the last 12 months, have you seriously considered attempting suicide?" was scored dichotomously, accepting only yes or no answers.

On the other hand, some aspects should be commended based on our outcomes. This study has high external validity, our findings are representative of the studied population, and can be cautiously extrapolated at the national level and to other developing countries. In addition, these results may serve as useful inputs for future public health strategies targeted at Brazilian adolescents, as it describes an alarming upward trend of suicidal ideation prevalence in adolescents over a 10-year period.

In conclusion, the present study found an increasing trend of suicidal ideation in adolescents. Social support, sleep quality, and parental supervision were the most important factors associated with suicidal ideation in adolescents, regardless of sex. Our findings suggest that 
schools might be the ideal location for interventions focusing on reducing suicidal ideation in this age group, because of potential benefits on each adolescent's social network. Policies targeting suicidal ideation in adolescents should account for the wide range of factors associated with this phenomenon.

\section{Acknowledgements}

This study was supported financially by Conselho Nacional de Desenvolvimento Científico e Tecnológico (CNPq; grant 432144/2016-1). JM was supported by the following grants: Fundação para a Ciência e a Tecnologia (FCT) SFRH/BSAB/142983/2018, UID/DTP/00617/2019, and Programa de Bolsas Santander Universidades 2018.

\section{Disclosure}

The authors report no conflicts of interest.

\section{References}

1 Bachmann S. Epidemiology of suicide and the psychiatric perspective. Int J Environ Res Public Health. 2018 Jul 6;15(7). pii: E1425. doi: 10.3390/ijerph15071425.

2 Hirsch JK, Rabon JK, Reynolds E, Barton AL, Chang EC. Perceived stress and suicidal behaviors in college students: conditional indirect effects of depressive symptoms and mental health stigma. Stigma Heal. 2017;4:98-106.

3 Bilsen J. Suicide and youth: risk factors. Front Psychiatry. 2018;9: 540.

4 Jaen-Varas D, Mari JJ, Asevedo E, Borschmann R, Diniz E, Ziebold $\mathrm{C}$, et al. The association between adolescent suicide rates and socioeconomic indicators in Brazil: a 10-year retrospective ecological study. Braz J Psychiatry. 2019;41:389-95.

5 Leenaars AA, Dieserud G, Wenckstern S, Dyregrov K, Lester D, Lyke J. A multidimensional theory of suicide. Crisis. 2018;39:416-27.

6 Lachal J, Orri M, Sibeoni J, Moro MR, Revah-Levy A. Metasynthesis of youth suicidal behaviours: perspectives of youth, parents, and health care professionals. PLoS One. 2015;10:e0127359.

7 Herbert A, Gilbert R, Cottrell D, Li L. Causes of death up to 10 years after admissions to hospitals for self-inflicted, drug-related or alcoholrelated, or violent injury during adolescence: a retrospective, nationwide, cohort study. Lancet. 2017;390:577-87.

8 Yu SS, Sung HE. Suicidal ideation of probationers. Gender differences. Crisis. 2015;36:424-32.

9 Turecki G, Brent DA. Suicide and suicidal behaviour. Lancet. 2016;387:1227-39.

10 Rueter MA, Holm KE, McGeorge CR, Conger RD. Adolescent suicidal ideation subgroups and their association with suicidal plans and attempts in young adulthood. Suicide Life Threat Behav. 2008;38: 564-75.

11 Chan MK, Bhatti H, Meader N, Stockton S, Evans J, O'Connor RC, et al. Predicting suicide following self-harm: systematic review of risk factors and risk scales. Br J Psychiatry. 2016;209:277-83.

12 Kokkevi A, Rotsika V, Arapaki A, Richardson C. Adolescents' selfreported suicide attempts, self-harm thoughts and their correlates across 17 European countries. J Child Psychol Psychiatry. 2012;53: 381-9.

13 Martins Junior DF, Felzemburgh RM, Dias AB, Caribé AC, BezerraFilho S, Miranda-Scippa Â. Suicide attempts in Brazil, 1998 - 2014: an ecological study. BMC Public Health. 2016;16:990.

14 Adrian M, Miller AB, McCauley E, Vander Stoep A. Suicidal ideation in early to middle adolescence: sex-specific trajectories and predictors. J Child Psychol Psychiatry. 2016;57:645-53.

15 Boeninger DK, Masyn KE, Feldman BJ, Conger RD. Sex differences in developmental trends of suicide ideation, plans, and attempts among European American adolescents. Suicide Life Threat Behav. 2010;40:451-64.

16 Klonsky ED, Qu T, Saffer BY. Recent advances in differentiating suicide attempters from suicide ideators. Curr Opin Psychiatry. 2017;30:15-20.

17 May AM, Klonsky ED. What distinguishes suicide attempters from suicide ideators? A meta-analysis of potential factors. Clin Psychol Sci Pract. 2016;23:5-20.

18 Belfort EL, Miller L. Relationship between adolescent suicidality, self-injury, and media habits. Child Adolesc Psychiatr Clin N Am. 2018;27:159-69.

19 Drapeau CW, Nadorff MR. Suicidality in sleep disorders: prevalence, impact, and management strategies. Nat Sci Sleep. 2017;9:213-26.

20 Shain B; Committee on Adolescence. Suicide and suicide attempts in adolescents. Pediatrics. 2016 Jul;138(1). pii: e20161420. doi: 10.1542/peds.2016-1420.

21 Zalsman G, Hawton K, Wasserman D, van Heeringen K, Arensman $E$, Sarchiapone $M$, et al. Suicide prevention strategies revisited: 10-year systematic review. Lancet Psychiatry. 2016;3:646-59.

22 de Carvalho PD, de Barros MVG, Santos CM, Melo EN, de Oliveira NKR, Lima RS. Prevalência e fatores associados a indicadores negativos de saúde mental em adolescentes estudantes do ensino médio em Pernambuco, Brasil. Rev Bras Saude Mater Infant. 2011;11:227-32.

23 Hosmer DW, Lemeshow S. Goodness-of-fit test for the multiple logistic regression model. Commun Stat. 1980;A10:1043-69.

24 Goldston DB, Molock SD, Whitbeck LB, Murakami JL, zayas LH, Hall GC. Cultural considerations in adolescent suicide prevention and psychosocial treatment. Am Psychol. 2008;63:14-31.

25 Chang EC, Sanna LJ, Hirsch JK, Jeglic EL. Loneliness and negative life events as predictors of hopelessness and suicidal behaviors in Hispanics: evidence for a diathesis-stress model. J Clin Psychol. 2010;66:1243-53.

26 Kobus K, Reyes O. A descriptive study of urban Mexican American adolescents' perceived stress and coping. Hisp J Behav Sci. 2000;22:163-78.

27 Winterrowd E, Canetto SS, Chavez EL. Friendship and suicidality among Mexican-American adolescent girls and boys. Death Stud. 2010;34:641-60.

28 Bernert RA, Joiner TE. Sleep disturbances and suicide risk: a review of the literature. Neuropsychiatr Dis Treat. 2007;3:735-43.

29 Sarchiapone M, Mandelli L, Carli V, losue M, Wasserman C, Hadlaczky G, et al. Hours of sleep in adolescents and its association with anxiety, emotional concerns, and suicidal ideation. Sleep Med. 2014; 15:248-54.

30 Pigeon WR, Pinquart M, Conner K. Meta-analysis of sleep disturbance and suicidal thoughts and behaviors. J Clin Psychiatry. 2012;73:e1160-7.

31 Cook CC. Suicide and religion. Br J Psychiatry. 2014;204:254-5.

32 Lawrence RE, Oquendo MA, Stanley B. Religion and suicide risk: a systematic review. Arch Suicide Res. 2016;20:1-21.

33 Lima NN, do Nascimento VB, de Carvalho SM, de Abreu LC, Neto $\mathrm{ML}$, Brasil $A Q$, et al. Childhood depression: a systematic review. Neuropsychiatr Dis Treat. 2013;9:1417-25.

34 McGirr A, Renaud J, Bureau A, Seguin M, Lesage A, Turecki G. Impulsive-aggressive behaviours and completed suicide across the life cycle: a predisposition for younger age of suicide. Psychol Med. 2008;38:407-17.

35 Calbo A, Busnello FB, Rigoli MM, Schaefer LS, Kristensen $\mathrm{CH}$. Bullying na escola: comportamento agressivo, vitimização e conduta pró-social entre pares. Context Clinic. 2009;2:73-80.

36 Mascayano F, Irrazabal M, D Emilia W, Vaner SJ, Sapag JC, Alvarado R, et al. Suicide in Latin America: a growing public health issue. Rev Fac Cien Med Univ Nac Cordoba. 2007;72:295-303.

37 Claumann GS, Pinto A de A, Silva DAS, Pelegrini A. Prevalência de pensamentos e comportamentos suicidas e associação com a insatisfação corporal em adolescentes. Braz J Psychiatry. 2018;67: 3-9.

38 Veras JL, Ximenes RC, de Vasconcelos FM, Sougey EB. Prevalence of suicide risk among adolescents with depressive symptoms. Arch Psychiatr Nurs. 2016;30:2-6. 